\title{
CULPADO, ATÉ QUE SE PROVE O CONTRÁRIO
}

Alessandra Correa Alves; Jacqueline Costa Borges; Paula dos Santos Bigoli; Thaís Fernanda Nunes de Brito

Universidade do Oeste Paulista - UNOESTE, Presidente Prudente, SP. E-mail leleca1988@gmail.com

\section{RESUMO}

O presente artigo tem como objetivo apresentar o princípio da presunção de inocência, que apesar de inserido na Constituição da República Federativa do Brasil (CRFB), têm mostrado pouca aplicação na ordem prática. $O$ trabalho destacará também a força da mídia como formadora de opinião, demonstrando o impacto que a veiculação de uma notícia mal elaborada pode trazer à vida de um indivíduo que é, por vezes, indevidamente considerado culpado por algum delito. Por fim, ficará demonstrado que a força empregada pelos meios de comunicação e mídias sociais para acusar alguém é exacerbada em relação àquela usada para demonstrar a sua inocência.

Palavras-chave: Direito. Processo Penal. Presunção de inocência. Prisão. Mídia.

\section{GUILTY UNTIL PROVEN INNOCENT}

\begin{abstract}
This article aims to conduct a hypothetical- deductive approach on the principle of presumption of innocence, which although inserted in the Constitution of the Federative Republic of Brazil (CRFB), have shown little practical application order. The work will also highlight the media's power as opinion forming, demonstrating the impact that the placement of a poorly written news can bring to the life of an individual who is sometimes wrongly convicted of a crime. Lastly, it will be shown that the force used by the media and social media to accuse someone is exacerbated compared to that used to demonstrate his innocence.
\end{abstract}

Keywords: Right. Criminal Procedure. Presumption of innocence. Prison. Media. 


\section{INTRODUÇÃO}

Atualmente vivemos em uma sociedade que de longe, não é nada segura. Em determinado horário, ao ligar a televisão, nos deparamos com um programa "jornalístico" que noticia os mais terríveis crimes. Mudamos de canal: a programação em massa é de igual teor. A mesma temática invade as redes sociais e folhetins online e, mesmo que você não esteja interessado em saber de tais notícias, os seus conhecidos, que visualizaram por esses meios, lhe passarão as informações. Não adianta fugir, de um jeito ou de outro, você saberá de algum crime que ocorreu no seu bairro, cidade, país, ou até mesmo, no exterior, e consequentemente, também saberá quem são os acusados de cometê-lo.

Diante dessa realidade, inúmeras pessoas são acusadas diariamente de cometer algum delito, sendo que, posteriormente, após o devido processo legal, algumas serão de fato condenadas, e outras, absolvidas.

Contudo, será que a absolvição de um acusado faz com que a sociedade o enxergue como inocente? Este artigo visa elucidar os nortes do processo penal e analisar a postura midiática e social, a fim de sanar essa problemática.

\section{METODOLOGIA}

O presente artigo desenvolveu-se por meio de levantamento de dados e informações em mídias virtuais, sites, livros, doutrinas, leis e jurisprudências pertinentes ao assunto. $\mathrm{O}$ método científico utilizado será o hipotético-dedutivo.

\section{LIBERDADE E GARANTIAS FUNDAMENTAIS SOB A LUZ CONSTITUCIONAL}

Quando um indivíduo é considerado culpado de cometer um crime, logicamente sofrerá efeitos de tal afirmação, que impactam diretamente sobre a sua liberdade, seja uma liberdade de locomoção ou quaisquer outras nuances da mesma. Portanto, é importante se fazer uma reflexão quanto às garantias fundamentais que existem para salvaguardar os direitos inerentes a todos, pois a liberdade é um bem precioso de todo ser humano, ser privado ou cerceado a esta dadiva deve estar corroborado com total segurança processual-jurídica e principalmente Constitucional.

A Constituição Federal, incorporou em seu texto legal o devido processo legal, nos seguintes termos: Art. 5o [...] LIV - "ninguém será privado da liberdade ou de seus bens sem o devido processo legal". O devido processo legal, consiste basicamente num procedimento ordenado, no qual o aplicador do Direito deve estar atento para não alcançar quaisquer dos interesses protegidos pela garantia constitucional. O conteúdo material do devido processo legal inibe o Estado de privar arbitrariamente os indivíduos de certos direitos fundamentais.

O processo penal é a garantia dada ao indivíduo de que seus direitos serão respeitados. A cláusula do devido processo legal estabelece ao acusado a garantia de ser processado conforme norma legalmente prevista. O Estado, ao buscar a sua pretensão punitiva não poderá afastar-se do que está previamente fixado pelo legislador.

Em todo processo existe o princípio do contraditório, porém, este tem maior importância no processo penal em virtude dos valores em questão. Defesa e contraditório estão intrincados, os dois são amostras do devido processo legal. No processo penal o contraditório deve ser integral, garantindo a estabilização de forças entre acusação e defesa.

Como forma de proteção ao direito de defesa do indivíduo, a Constituição Federal de 1988 inseriu mais uma garantia constitucional: o princípio da presunção de inocência ou da nãoculpabilidade. Constitui um princípio no qual ao seu redor é estabelecido todo o processo penal, formando assim, garantias para o imputado ante à ação punitiva do Estado, a partir do entendimento de que o imputado durante o processo penal é considerado inocente, diminuindose, assim, as medidas que reduzam seus direitos durante o processo. 
O referido princípio relacionado ao devido processo legal, é garantia pelo exercício dos direitos de liberdade (direitos fundamentais de natureza individual) enquanto a persecução penal, e não apenas de direitos fundamentais atinentes ao processo (tais como ampla defesa, contraditório, juiz natural e outros mais). É uma garantia de natureza geral.

Este princípio é uma enorme conquista no decurso da História e objetiva a proteção do imputado. Qualquer cidadão é de supostamente inocente durante o processo, ou seja, enquanto não decisivamente condenado, conjectura-se o réu inocente, não podendo ver-se discriminado social, moral nem fisicamente diante de outros cidadãos.

\section{PRISÃO SEM TRÂNSITO EM JULGADO}

Como mencionado, a constituição federal de 1988 estabelece em seu artigo 5o, inciso LVII que "ninguém será considerado culpado até o trânsito em julgado de sentença penal condenatória". Consoante texto legal, é possível notar que a regra é a liberdade do indivíduo, sendo sua prisão, exceção; trata-se da presunção de inocência.

Algumas exceções, são as chamadas prisões provisórias, que implicam na custódia anterior ao trânsito em julgado. Segundo, Damásio de Jesus (2015, p. 257), prisão provisória (ou ainda, prisão cautelar) é "medida que busca assegurar a eficácia do provimento jurisdicional a ser ditado. [É] (...) um instrumento destinado a garantir o bom andamento da persecutio criminis ou a efetividade da condenação penal".

Considerada uma prisão processual, a prisão provisória é gênero do qual se extraem algumas espécies, dentre elas a prisão em flagrante (arts. 301 a 310 do CPP), prisão temporária (Lei $n^{\circ} 7.960 / 89$ ) e prisão preventiva (arts. 311 a 316 do CPP).

Segundo definição de Capez (2015, p. 297), a prisão em flagrante é:

(...) medida restritiva da liberdade, de natureza cautelar e processual, consistente na prisão, independente de ordem escrita do juiz competente, de quem é surpreendido cometendo, ou logo após ter cometido, um crime ou uma contravenção.

A prisão Temporária, segundo exprime Fernando Capez (2013, p. 165), é a "prisão cautelar de natureza processual destinada a possibilitar as investigações a respeito de crimes graves, durante o inquérito policial". Essa modalidade de prisão processual só pode ser aplicada na fase de investigação criminal (inquérito), por cinco dias (prorrogáveis por mais cinco) aos crimes constantes do artigo 10, inciso III da Lei 7960/89. Nesse diapasão, contribui o entendimento de Damásio de Jesus e Antônio Magalhães (apud CAPEZ, 2013, p. 166):

(...) a prisão temporária só pode ser decretada naqueles crimes apontados pela lei, desde que concorra qualquer uma das duas primeiras situações. Assim, se a medida for imprescindível para as investigações ou se o endereço ou identificação do indiciado forem incertos, caberá a prisão cautelar, e se o crime for um dos indicados por lei.

Por fim, existe a prisão preventiva, consistente no cárcere do indivíduo, também antes do término da persecução penal, com intuito de garantir a efetividade do processo, não possuindo, portanto, caráter satisfativo. Não possui prazo para a sua duração determinado em lei, mas deve atender aos princípios da proporcionalidade e necessidade.

Nesse sentido, assinala o STF: 
A prisão preventiva supõe prova da existência do crime (materialidade) e indício suficiente de autoria; todavia, por mais grave que seja o ilícito apurado e por mais robusta que seja a prova de autoria, esses pressupostos, por si sós, são insuficientes para justificar o encarceramento preventivo (...). A tais requisitos deverá vir agregado, necessariamente, pelo menos mais um dos seguintes fundamentos, indicativos da razão determinante da medida cautelar: a) a garantia da ordem pública; b) a garantia da ordem econômica; c) a conveniência da instrução criminal ou; d) a segurança da aplicação da lei penal.

Ademais, essa medida cautelar somente se legitima em situações em que ela for o único meio eficiente para preservar os valores jurídicos que a lei penal visa a proteger, segundo o art. 312 do Código de Processo Penal. Ou seja, é indispensável ficar demonstrado que nenhuma das medidas alternativas indicadas no art. 319 da lei processual penal tem aptidão para, no caso concreto, atender eficazmente aos mesmos fins, nos termos do art. 282, $\S 6^{\circ}$, do Código de Processo Penal.

Conclui-se, portanto, que em todas as modalidades supra, faz-se necessária a existência do fumus commissi delicti e periculum libertatis, bem como outros requisitos aplicáveis, sem mencionar o fato de todas as prisões citadas não possuírem caráter de condenação. Entretanto, o que se observa no atual contexto da sociedade é uma busca incessante por prisão a todo custo (quando não, por justiça com as próprias mãos).

Ocorre que, a manutenção de um indivíduo em cárcere, sem que haja a devida comprovação da autoria do delito, e consequente trânsito em julgado, pode implicar em consequências gravíssimas e danos irreparáveis à vida do indiciado.

\section{NOTÍCIAS ERRADAS: PORQUE A MÍDIA NÃO DÁ A DEVIDA ATENÇÃo À REPARAÇÃO?}

Os meios de comunicação nas suas diversas formas (televisão, rádio, jornal, revistas, internet, etc.), são meios eficazes e cada vez mais ágeis para a propagação de ideias. Acontece que, deve ser sopesado como estas informações vão ser absolvidas pelo público. Os instrumentos midiáticos influenciam na construção e compreensão da realidade ao transmitir acontecimentos e opiniões, exercendo uma espécie de controle social de forma indireta, ditando comportamentos e disseminando ideologias, de modo que a opinião pública é construída sob forte influência da mídia.

A imprensa não acusa formalmente alguém da prática de um crime, mas a cobertura jornalística, muitas vezes, toma uma postura julgadora e acusadora, condenando o investigado de forma antecipada, gerando um pré-convencimento na população.

As matérias que deveriam ter cunho informativo, noticiando apenas o fato e a realidade para aqueles que a desconhecem, tornam-se matérias sensacionalistas, onde os jornalistas, ao fazer a mediação, noticiando fatos recentes, já pressupõem os acontecimentos futuros, oferecendo ao público um conceito fechado, impermeável, imponderável - um pré-juízo. A função social da imprensa e suas premissas éticas são deixadas de lado, diante da frenética busca por audiência e maiores lucros com publicidade. A mídia elege determinados cidadãos, e transfere para si a sede do julgamento, não se importando se são culpados ou inocentes.

Vale relembrar casos divulgados pelos instrumentos midiáticos que causaram injustiça aos investigados: Irmãos Naves em 1937, Escola Base em 1994, Bar Bodega em 1996, Heberson Lima em 2003 e Daniela Toledo em 2006. Esses são alguns nomes que ficaram conhecidos antes de serem absolvidos. 
A cobertura jornalística tem efeito destrutivo, pois gera um pré-convencimento antecipado na população de que os investigados devem ser, de fato, condenados. Esta conjetura não está afrontando só os princípios constitucionais da presunção de inocência, do devido processo legal, do contraditório e da ampla defesa, além dos sagrados direitos à intimidade, à imagem e à honra, todos assegurados constitucionalmente, ocasionalmente esse préconvencimento faz com que a população tome atitudes irracionais contra esses investigados e cometam barbáries, violando também a integridade física, psicológica, moral dos investigados, como é o caso de Daniela Toledo, que não pode velar a própria filha e quando presa, foi espancada por suas companheiras de cárcere; ou de Herberson Lima que também foi espancado e estuprado por outros encarcerados, contraindo o vírus HIV.

Segundo Ranulfo Freire (2004) "a liberdade de imprensa, (...) tratada de forma descuidada, desborda na ofensa aos Direitos Humanos", e por mais que absolvidos, a condenação midiática persiste na consciência da população, fazendo-lhes crer que a "justiça" não tenha sido feita. Sendo esses investigados absolvidos, são permanentemente estigmatizados de forma irreparável.

O fato é que a imprensa exerce papel de fundamental importância na sociedade livre e pluralista. No entanto, difamar pessoas por meio de notícias sensacionalistas de forma acusatória e parcial, sem medir consequências dos atos, extrapola o dever de informar, ostentando pouca ou nenhuma ética.

Pois bem, afinal, ao descobrir o equívoco, porque a mídia não dá a devida atenção à reparação? O processo judicial é moroso e as pessoas se fundam no momento em que o investigado é exposto pela suposta prática de um crime. Esquecem, pois, de buscar o resultado daquela acusação. Outrossim, as mídias, por vezes, não expõem seus erros e permanecem com a ideia inicialmente exposta ao público, de que é realmente o investigado o autor daquela conduta reprovável. Embora utilizem-se das expressões acusado ou investigado, o contexto em que elas são empregadas, conotam a certeza de condenação.

Diante desta situação, vale polemizar a possibilidade de um controle eficaz e uma fiscalização rígida sobre os órgãos da mídia, visando impedir abusos e injustiças, já que as liberdades de imprensa e de expressão não podem violar a dignidade da pessoa humana do acusado, com fundamento no princípio da presunção de inocência. (SANTOS, 2010).

\section{PAPEL DOS OPERADORES DO DIREITO NA CONSCIENTIZAÇÃO DA SOCIEDADE}

Quando se utiliza referencias de termos jurídicos como: o princípio da presunção da inocência ou o devido processo legal, todo operador do direito já tem um entendimento claro em sua mente de seu real significado, pois já está habituado com tais informações que fazem parte de seu cotidiano. Mas por obvio, não acontece a mesma coisa com a sociedade leiga, que muitas vezes não tem esse mesmo discernimento. Por isso é demasiadamente fundamental aquele que possui o privilégio de ter esses conhecimentos difundir, passar adiante para que se possa construir cada vez mais uma sociedade justa e equilibrada.

Aquele que tem informação, tem uma poderosa ferramenta em suas mãos, principalmente nos dias atuais, com o avanço tecnológico e de comunicação. Porém, se usada sem o conhecimento correto pode fazer grandes estragos, como transformar um inocente em culpado.

A sociedade possui as informações, mas os operadores do direito possuem o conhecimento, e com esse conhecimento vem também a missão de divulgar ao máximo as pessoas para que elas possam dar sua opinião, agora não mais baseadas apenas em boatos, mas argumentos sólidos de quem é perito do assunto.

\section{CONCLUSÃO}


É visível a possibilidade de se ocorrer erros durante um processo penal. Justamente por isso, é que toda atenção deve ser despendida para que, somente após um julgamento inequívoco, determine-se que um indivíduo seja considerado culpado pela prática de algum crime.

Entretanto, existem fatores que ensejam à culpabilidade social antecipada. As prisões provisórias, por exemplo, por muitas vezes, excedem todos os limites temporais e se estendem durante meses e até mesmo anos. Durante esse período, o indivíduo que foi divulgado como autor de um crime, continuará sendo conhecido como tal.

Na prisão não há jornais, programas de televisão ou qualquer outro meio que possibilite ao réu exercer o seu direito de defesa social. Ele deve se contentar apenas com a defesa jurídica, e rezar para que a máquina do Judiciário olhe seu caso com um pouco mais de atenção.

A mídia por sua vez, já cumpriu o seu papel: fez inúmeras matérias e reportagens ilustrando o quanto o autor praticou os crimes com total monstruosidade. A narrativa de tais fatos são por vezes fantasiosas e criativas, cheias de acusação e reprovação. É isso que aumenta a audiência.

Futuramente, caso ocorra uma absolvição de um desses casos, quase ninguém ficará sabendo. Em alguns, a absolvição é vista com maus olhos: "onde já se viu?", "será mesmo que ela é inocente?".

Ora, a pergunta que deveria ter sido feita desde o início era: "será mesmo que ela é culpada?". Temos todos que lutar pela garantia de nossos direitos, afinal, podemos estar em uma situação parecida no futuro. Aliás, somente colocando-nos na posição de acusado é que percebemos o quão agressiva é a postura midiática e social. Imagine você, sofrendo pela morte da própria filha, ser acusado de matá-la?

Mas, afinal, o que é necessário para que a sociedade mude sua maneira de agir e pensar? Com certeza, informação. Faltam profissionais que se encarreguem de demonstrar a importância da presunção de inocência e a necessidade de ponderar provas e fatos de forma racional, sem apelar para a paixão. Mas se aqueles que transmitem a notícia são os que mais julgam e condenam, como a sociedade será imparcial?

Infelizmente, a resposta ao questionamento inicial feito no presente artigo, é negativa. A sociedade em geral não enxerga como inocente aquele que é absolvido no processo penal. $\mathrm{Na}$ prática, todo aquele que é acusado de cometer um crime, é considerado culpado, até que se prove o contrário.

\section{BIBLIOGRAFIA}

CAPEZ, Fernando. Código de Processo Penal Comentado. 1 ed. São Paulo: Saraiva, 2015.

CAPEZ, Fernando. Processo penal simplificado. 20 ed. São Paulo: Saraiva, 2013.

FREIRE, Ranulfo de Melo. O papel da mídia na democracia. 1 ed. São Paulo: Boletim do IBCCRIM, 2004.

GOMES, Luiz Flávio. Prisão preventiva do Lula: Posição do STF sobre a preventiva. Disponível em: <https://jus.com.br/artigos/47248/prisao-preventiva-do-lula-posicao-do-stf-sobre-a-preventiva>. Acesso em: 06 jul. 2016

JESUS, Damásio de. Código de Processo Penal Anotado. 27 ed. São Paulo: Saraiva, 2015.

KÕNIG, M. Suspeitos são expostos em demasia na mídia. Gazeta do Povo, Curitiba, 26 de jul. de 2010. Disponível em: <http://www.gazetadopovo.com.br/vida-e-cidadania/suspeitos-saoexpostos-em-demasia-na-midia-2wpn273qtm5ej82ahoekz1r9q>. Acesso em: 27 jul. 2016. 
NACIF. E. R. A mídia e o processo penal. Observatório da Imprensa, São Paulo, 28 dez. 2010. Disponível em: <http://observatoriodaimprensa.com.br/caderno-da-cidadania/a-midia-e-oprocesso-penal-23316/> Acesso em: 27 jul. 2016.

SANTOS, Moisés da Silva. Influência da mídia e presunção de inocência. Disponível em: <https://jus.com.br/artigos/23994/a-influencia-dos-orgaos-da-midia-nos-crimes-de-granderepercussao-social-em-face-da-presuncao-de-inocencia-do-acusado/1>. Acesso em: 27 de jul. 2016. 